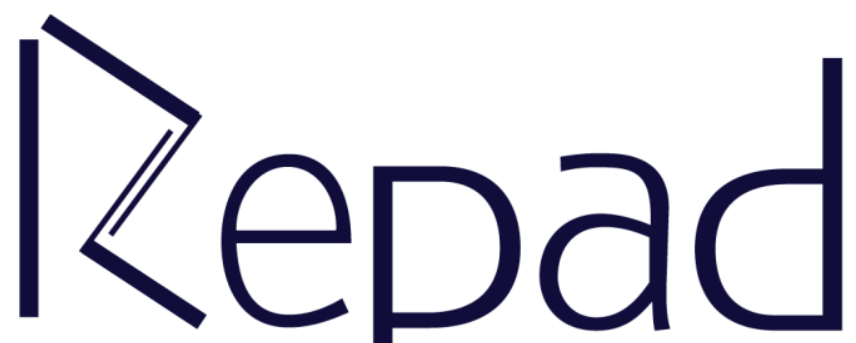

Revista Estudos e

Pesquisas em Administração 


\title{
LIMITAÇÕES E DESAFIOS NAS ATIVIDADES GRUPAIS DE PROFESSORES DE MATEMÁTICA E CIÊNCIAS DA NATUREZA: Um estudo em escolas estaduais de Tangará da Serra - MT
}

Felipe Guedes Moreira Vieira felipeguedesvieira@gmail.com https://orcid.org/0000-0002-3193-7045

Instituto Federal de Mato Grosso Tangará da Serra, Mato Grosso, Brasil

Katia Valeria Alves de Lima https://orcid.org/0000-0002-3568-9181

Instituto Federal de Mato Grosso Tangará da Serra, Mato Grosso, Brasil

\author{
Andre Luis Scudeler \\ https://orcid.org/0000-0002-1286-053X \\ Instituto Federal de Mato Grosso \\ Tangará da Serra, Mato Grosso, Brasil \\ Nicolas da Silva de Lima \\ https://orcid.org/0000-0003-3918-9974 \\ Instituto Federal de Mato Grosso \\ Tangará da Serra, Mato Grosso, Brasil \\ Thaynára Orrana Pereira Pareci \\ https://orcid.org/0000-0003-4554-5904 \\ Instituto Federal de Mato Grosso \\ Tangará da Serra, Mato Grosso, Brasil
}

\begin{abstract}
RESUMO
A denominação de satisfação no trabalho constitui um conjunto de atitudes refletidas no meio organizacional, as quais mostram a perspectiva do trabalhador acerca de seu emprego. Sendo assim, a satisfação no trabalho é um aspecto fundamental a ser tratado dentro das organizações, já que a mesma lida diretamente com o comportamento e bem estar dos colaboradores. Especificamente em ambiente escolar, reforça-se a importância da satisfação dos docentes, sendo eles o pilar principal para o bom funcionamento do sistema educacional brasileiro. Nesta pesquisa foi proposta uma abordagem delimitada relacionada à satisfação no trabalho, com o objetivo de analisar a atuação dos professores das áreas de matemática e ciências da natureza nas escolas estaduais de ensino médio da zona urbana de Tangará da Serra-MT. Para isso, foram realizados estudos bibliográficos além de pesquisa qualitativa dirigida aos entrevistados, a qual obteve resultados ligeiramente positivos na avaliação de satisfação ante as limitações e desafios no desempenho de trabalho coletivo pelos docentes.
\end{abstract}

Palavras-chave: Satisfação de Professores, Ambiente de Trabalho, Matemática, Ciências da Natureza. 


\title{
LIMITATIONS AND CHALLENGES IN GROUP ACTIVITIES OF MATHEMATICS AND SCIENCE TEACHERS: A study in Tangará da Serra-MT state schools
}

\begin{abstract}
The denomination of job satisfaction is a set of attitudes reflected in the organizational environment, which show the perspective of the worker about his job. Thus, job satisfaction is a key aspect to be addressed within organizations, as it deals directly with the behavior and well-being of employees. Specifically in the school environment, the importance of teacher satisfaction is reinforced, as they are the main pillar for the proper functioning of the Brazilian educational system. This research proposes a delimited approach related to job satisfaction, aiming to analyze the performance of teachers of mathematics and nature sciences in the state high schools of the urban area of Tangará da Serra-MT. To this end, bibliographic studies were carried out, as well as qualitative research directed to the interviewees, which obtained slightly positive results in the satisfaction assessment before the limitations and challenges in the collective work performance by the teachers.
\end{abstract}

Keywords: Teacher Satisfaction, Work Environment, Mathematics, Natural Sciences.

Submetido: 29/11/2019

Aceito: 30/01/2020

Publicado: 31/01/2020

\section{INTRODUÇÃO}

Dentro do ambiente de trabalho há diversos fatores que interferem no desenvolvimento das atividades individuais, fatores estes como ruídos, falta de comunicação e estrutura, escassez de materiais, dentre outras variáveis. Nessa ótica, tais aspectos podem influenciar nas atitudes e principalmente na satisfação do colaborador. Nesse contexto, as tarefas desempenhadas pelo funcionário comprometem a qualidade dos serviços e consequentemente as demais rotinas organizacionais.

Tendo uma base sobre os problemas decorrentes no trabalho, este artigo partiu do interesse de investigar se os docentes se encontram satisfeitos para o bom exercício de suas atividades, tendo em vista as limitações e desafios existentes. Em um contexto geral, objetivou-se analisar as limitações e desafios dos professores das áreas de exatas e ciências da natureza nas escolas estaduais de ensino médio de Tangará da Serra-MT. Já os objetivos específicos se dedicaram a analisar a satisfação dos professores das áreas pelo aspecto institucional, além de compreender a inter-relação destes profissionais inseridos na instituição de ensino. Justifica-se a importância da satisfação no trabalho de professores do ensino médio como essencial para o bom resultado do processo de ensinoaprendizagem de jovens e adolescentes das escolas públicas, mostrando-se ainda necessária para evitar um prejuízo ao bem-estar do profissional em situações de excessiva carga de trabalho.

O tema satisfação é um assunto que vem ganhando muito espaço dentro das discussões organizacionais. Vários autores se dedicaram ao estudo, a saber: Siqueira (2008), Zanelli, Borges-andrade e Bastos (2004), Spector (2003), Siqueira e Padovam 
(2008), Alves, Azevedo e Gonçalves (2014), Bogler e Nir (2012), Ferreira (2011), Robbins (2010), entre outros. Foram realizados estudos bibliográficos com base na literatura da área, além de uma pesquisa qualitativa com o objetivo de obter dados a respeito da satisfação de docentes. Essas informações foram posteriormente tabuladas a fim de auxiliar no desenvolvimento e apresentação desse artigo, obtendo-se ao final resultados relativamente equilibrados entre a satisfação e insatisfação, porém, com tendência positiva.

Com base nos estudos realizados, percebe-se que a satisfação no trabalho é a base para que as atividades organizativas obtenham êxito. Em vista disso, faz-se necessária a intervenção do gestor no meio organizacional, destinando-se à coordenação no ambiente escolar o papel de identificar e encontrar soluções para os problemas que geram insatisfação, sejam decorrentes da estrutura física ou aspectos comportamentais que comprometam o bom funcionamento das rotinas de trabalho.

A seguir, conceitua-se a satisfação no trabalho, com base em estudos já desenvolvidos, que darão respaldo teórico a esta pesquisa. Posteriormente, são apresentados os métodos que subsidiaram a pesquisa e, na sequência, são discutidos os resultados encontrados com base nas suas possíveis causas. As considerações finais possibilitam a construção de um panorama geral com vistas à realidade observada durante a execução desta pesquisa.

\section{A SATISFAÇÃO NO TRABALHO}

Já nas primeiras décadas do século XX a satisfação em âmbito empresarial recebia suas primeiras pesquisas, mas sempre relacionada com a motivação, no sentido de elevar o ânimo dos indivíduos para o trabalho, aumentando a produtividade e diminuindo índices de absenteísmo. Na década de 1970 as pesquisas começaram a tratar da satisfação como componente da atitude, porém mantendo a relação com a produtividade, fato que exigiu das empresas um maior grau de responsabilidade para com a satisfação dos funcionários (SIQUEIRA, 2008). A partir de 1990 as pesquisas incluíram as emoções e passou-se a observar a relação da satisfação com o afeto, tanto positivo quanto negativo (ZANELLI; BORGES-ANDRADE; BASTOS, 2004).

No início do século XXI a satisfação recebia inúmeros conceitos, relacionados com a afetividade presente no ambiente de trabalho. Nesse momento começou a ser entendida também como consequência do ambiente da empresa. Siqueira (2008, p. 266) afirma que satisfação "é apontada como um dos três componentes psicossociais do conceito de bem-estar no trabalho, ao lado de envolvimento com o trabalho e comprometimento organizacional afetivo". Com isso, a satisfação no trabalho passa a ser considerada como um fator de extrema importância para a criação de um ambiente de trabalho agradável, que não cause muito desgaste físico e psicológico aos colaboradores (SIQUEIRA; PADOVAM, 2008).

Robbins (2010, p. 73) conceitua amplamente a satisfação com o trabalho como "um sentimento positivo resultante de uma avaliação de suas características". Portanto, a partir do ponto que há a presença da satisfação no trabalho, o colaborador estará mais propenso a manifestar sentimentos positivos, ou, na ausência dessa, poderá ter sentimentos negativos.

De acordo com Zanelli, Borges-andrade e Bastos (2004) e Spector (2003), a satisfação no trabalho é um representativo de atitude variável, que mostra como os indivíduos se sentem no local de trabalho, seja considerando o ambiente como todo ou 
apenas relacionando-a a alguns de seus aspectos (ZANELLI; BORGES-ANDRADE; BASTOS, 2004; SPECTOR, 2003).

Deste modo, a satisfação pode ser avaliada na medida em que há o sentimento positivo na realização do trabalho. Com isso é fundamental que a organização entenda a satisfação do empregado como os valores, atitudes e objetivos pessoais que precisam ser reconhecidos e estimulados, para que esses se sintam motivados a exercer o cargo dentro da empresa (SPECTOR, 2003).

Pode-se dizer que a satisfação está ligada a vários aspectos da organização, ou seja, um impacto na empresa pode estar relacionado com a satisfação e o desempenho no ambiente organizacional. Spector (2003, p. 241) apresenta dois aspectos que mostram diferentes características, onde a primeira caracteriza o desempenho como meio para alcançar satisfação e a última expõe a satisfação como forma de obter melhor desenvolvimento e, consequentemente, realizar as atividades com maior efetividade.

\section{ATIVIDADES GRUPAIS E SATISFAÇÃO DOS DOCENTES}

Partindo para a satisfação dos trabalhadores de escolas, mais especificamente os professores, pode-se dizer que estudos relacionados à atuação dos mesmos já estavam sendo realizados na década de 1960, quando havia uma boa base de pesquisas envolvendo docentes, tanto relacionadas aos motivos de escolha de profissão, como voltadas para expectativas em alcançar satisfação na profissão (ALVES; AZEVEDO; GONÇALVES, 2014).

A satisfação do professor já era admitida como importante, por afetar diretamente na maneira com que realizam suas tarefas, haja vista que possibilita maior entusiasmo e determinação na docência, impactando diretamente no aprendizado e, consequentemente, um maior comprometimento por parte do docente para se dedicar ao seu crescimento profissional (BOGLER; NIR, 2012). Apesar de já haver inúmeras pesquisas voltadas ao tema, Klassen, Usher e Bong (2010) apontam a necessidade de serem realizados mais estudos para um melhor entendimento do sistema de ensino.

A percepção de realização profissional é dada, de modo geral, por inúmeras influências e acontecimentos decorrentes do cotidiano no trabalho, envolvendo o convívio no ambiente de trabalho tanto com a estrutura física de qualidade quanto com a interação social, sendo necessário a presença de emoções positivas relacionadas à área de atuação e estabilidade psicológica (FERREIRA, 2011).

Com base nessas considerações, o ambiente físico e a infraestrutura apresentam impacto para a satisfação no trabalho (PEREIRA; ENGELMANN, 1993). Assim, podese perceber que, se o local estiver proporcionando um ambiente agradável, mesmo com muitas horas no trabalho, os indivíduos estarão motivados e com maior envolvimento para atender aos objetivos propostos pela instituição (PIZZOLI, 2005).

Não só o ambiente físico, mas também as relações sociais são fatores que alteram o nível de satisfação, principalmente, no que se refere ao intuito da profissão, isto é, transmitir conhecimento a um grupo. Desse modo, os comportamentos grupais, relacionando-os a um ideal de eficácia do coletivo, apresentam a capacidade de induzir indiretamente a satisfação no trabalho dos indivíduos, interferindo no todo, quando mensurada a partir de quatro diretrizes, sendo elas: satisfação com a vida, progresso de objetivos, afeto positivo no ambiente de trabalho e apoio em alcançar metas (RAMOS et al., 2016). Portanto, o desenvolvimento grupal atinge a satisfação dos docentes variavelmente conforme a sua condição, podendo ser uma inter-relação boa ou ruim, 
consequentemente ser um benefício ou uma limitação para a execução de suas atividades, dependendo da forma que está sendo trabalhada na instituição de ensino.

Para Rebolo e Bueno (2014), na edificação do bem-estar dos profissionais da educação, o bom relacionamento grupal é um dos principais propulsores para se atingir o ideal do bom convívio. Por conseguinte, quando há a presença de relações interpessoais conflituosas no exercício de suas atividades, a interação será uma fonte de mal-estar, que resultará no isolamento individual e na dificuldade de solucionar conflitos. Nesse contexto, entra, principalmente, o papel dos coordenadores das instituições em dialogar com os demais funcionários, tendo em vista que, se o docente não receber o apoio institucional adequado, sua motivação será afetada diretamente no envolvimento com as várias exigências e responsabilidades demandadas pelo cargo (GARCIA; OLIVEIRA; BARROS, 2008).

Portanto, reforça-se que, para que as atividades de ensino tenham eficácia, é fundamental que os docentes assumam uma postura diferenciada de trabalho coletivo e colaborativo. A esse respeito, os autores Fullan e Hargreaves (2001 apud BOY; DUARTE, 2014, p. 86) dizem que são necessários ao envolvimento grupal na função desses docentes o "[...] engajamento e a responsabilização coletiva entre os professores, trabalho de discussão coletiva, de experimentação em sala de aula e avaliação posterior coletiva, além da preocupação em garantir tempos e espaços de trabalho coletivo".

Nessa perspectiva de trabalho grupal, os docentes precisam encontrar significado nas ações conjuntas (BORGES, 2006 apud BOY; DUARTE, 2014). Desse modo, a satisfação é influenciada pelo sentido que os indivíduos percebem nos trabalhos em equipe.

\section{METODOLOGIA}

A pesquisa foi realizada durante o mês de março de 2019, buscando avaliar a satisfação de docentes do ensino médio regular das áreas de matemática e ciências da natureza quanto ao ambiente de trabalho e atividades grupais. Possui natureza bibliográfica, conforme explica Gil (2007, p. 44), pois “é desenvolvida com base em material já elaborado, constituído principalmente de livros e artigos científicos". É classificada como exploratória, ao passo que "tem como objetivo proporcionar maior familiaridade com o problema, com vistas a torná-lo mais explícito ou a construir hipóteses" (GIL, 2007, p. 41). Configura-se ainda como pesquisa qualitativa.

Para a coleta de dados, foram aplicados questionários aos docentes contendo oito perguntas fechadas, e uma pergunta aberta, esta com o objetivo de obter informações extras, caso julgasse importante. A amostra abordada foi de 40 docentes que se dispuseram a participar de um total de 55 profissionais, correspondendo a aproximadamente de $73 \%$ dos professores das cinco escolas estaduais de ensino médio da zona urbana do município de Tangará da Serra-MT, sendo esses lotados nas áreas de matemática, física, química e biologia.

Inicialmente, consultado o número de docentes presentes nas escolas, foram elaborados os questionários para a coleta dos dados, sendo eles entregues a todos os professores das referentes áreas de ensino que se disponibilizaram a participar da pesquisa, juntamente com um ofício que descrevia os objetivos da mesa. Após a coleta de dados, os mesmos foram tabulados e apresentados por meio de tabelas, e, então, analisados quanto às possíveis causas relacionando os dados com a teoria. 


\section{RESULTADOS E DISCUSSÕES}

A pesquisa de campo realizada em escolas estaduais da zona urbana do município de Tangará da Serra-MT resultou no total de 40 formulários preenchidos a respeito da satisfação de professores do ensino médio das disciplinas de matemática, física, química e biologia. Os dados tabulados revelam uma amostra das percepções de satisfação do referente público questionado. As oito perguntas fechadas, foram pensadas para identificar se os aspectos físicos e de infraestrutura das escolas em que esses docentes exercem sua profissão interferem de algum modo em sua satisfação. E ainda, caso o professor quisesse acrescentar informações relevantes à pesquisa, tinha a opção da pergunta aberta.

A primeira pergunta elaborada questionava se há suporte das coordenações para atender às demandas dos professores, baseando-se no que os autores Lima e Santos (2007) mencionaram sobre a importância da relação docente e coordenação, a qual necessita garantir o máximo de suporte para que juntos possam realizar as tarefas com o mínimo de desgaste possível, e assegurar o equilíbrio emocional desses.

Conforme Tabela 1, foi relatado que $85 \%$ dos docentes consideram o auxílio das coordenações escolares bastante ou totalmente aplicável, $15 \%$ razoavelmente aplicável, e não houve nenhuma resposta relacionada à pouca ou ausência de suporte. Estes resultados em termos educacionais são de extrema importância, visto a importância do papel da coordenação no intermédio das necessidades dos professores ao realizarem suas tarefas (LIMA; SANTOS, 2007). Logo, trata-se de um fator que está contribuindo para a satisfação dos professores de exatas e ciências da natureza no exercício de sua profissão.

Tabela 1. Há suporte das coordenações para o acompanhamento da demanda escolar?

\begin{tabular}{lc}
\multicolumn{1}{c}{ Alternativas } & Porcentagem de respostas \\
\hline Não se aplica de nenhum modo. & $0 \%$ \\
Pouco se aplica. & $0 \%$ \\
Aplica-se razoavelmente. & $15 \%$ \\
Aplica-se bastante. & $55 \%$ \\
Aplica-se totalmente. & $30 \%$ \\
\hline
\end{tabular}

Fonte. Elaborado pelos autores, com base nos dados da pesquisa (2019)

O segundo questionamento, dirigido aos docentes, repercute em suas demandas para uma melhor atuação profissional. Assim, conforme Tabela 2, percebe-se que 52\% dos docentes estão se sentido bastante ou totalmente contemplados, ou seja, não há motivos para terem insatisfação com falta de voz em reuniões pedagógicas, tendo então livre capacidade de opinar, sugerir e requisitar melhorias para o ambiente de trabalho. Tal resultado é importante e reforça o exposto por Coutinho (2002) quando mostra que ser ouvido dentro de organizações eleva a satisfação pessoal.

Tabela 2. As áreas de exatas e ciências da natureza são contempladas pelas reuniões pedagógicas?

\begin{tabular}{lc}
\multicolumn{1}{c}{ Alternativas } & Porcentagem de respostas \\
\hline Não se aplica de nenhum modo. & $2 \%$ \\
Pouco se aplica. & $15 \%$ \\
Aplica-se razoavelmente. & $30 \%$ \\
Aplica-se bastante. & $28 \%$ \\
Aplica-se totalmente. & $25 \%$ \\
\hline
\end{tabular}

Fonte. Elaborado pelos autores, com base nos dados da pesquisa (2019) 
Já 30\% considera que tal contemplação de necessidades não é nula, mas precisa ser levada com maior importância, e $17 \%$ julgaram serem pouco ou de nenhum modo contemplados pelas reuniões pedagógicas, logo, tal percentual considera que suas participações em reuniões são inúteis, o que gera para esses certa insatisfação.

A terceira pergunta envolve os recursos didáticos ofertados pela instituição de ensino, os quais foram considerados para o atendimento das necessidades pedagógicas envolvendo o desenvolvimento de aulas. Nessa perspectiva, há estudos que apontam sobre a importância da estrutura física para um maior bem-estar ao trabalhar, conforme classificado por Herzberg (1976), o fator higiênico do trabalho em suas pesquisas motivacionais, ou seja, a estrutura do ambiente de trabalho é caracterizada como fundamental para a satisfação dos funcionários, visto que, sendo essa estrutura precária, decorrerá em insatisfação nos mesmos (ZANELLI; BORGES-ANDRADE; BASTOS, 2004; SPECTOR, 2003).

Tabela 3. Os recursos didáticos da instituição são suficientes para as atividades de ensino como livros, salas de estudos, recursos multimídias e laboratórios?

\begin{tabular}{l|c}
\hline \multicolumn{1}{c}{ Alternativas } & Porcentagem de respostas \\
\hline Não se aplica de nenhum modo. & $0 \%$ \\
Pouco se aplica. & $8 \%$ \\
Aplica-se razoavelmente. & $42 \%$ \\
Aplica-se bastante. & $42 \%$ \\
Aplica-se totalmente. & $8 \%$ \\
\hline
\end{tabular}

Fonte. Elaborado pelos autores, com base nos dados da pesquisa (2019)

Dentre os questionados, conforme Tabela 3, 50\% considera que os materiais como livros, recursos multimídias, laboratórios e salas de estudos presentes em suas respectivas escolas, atendem totalmente para que as aulas de matemática, física, química ou biologia possam ser realizadas dentro do planejado.

Porém, $42 \%$ julga os recursos como razoáveis, sendo até certo ponto suficientes, mas tendo muito a melhorar, já $8 \%$ classificam como pouco suficiente, tendo materiais talvez no máximo para aulas básicas, e insuficientes para realizar uma boa dinâmica em sala. A referente falta de estrutura afeta diretamente na falta de motivação desses professores, que em situações mais favoráveis conseguiriam desenvolver os conteúdos de maneira mais eficaz e produtiva, com alunos aprendendo mais e, consequentemente, o professor consegue ter uma maior satisfação a respeito de sua capacidade profissional.

É importante ressaltar a situação financeira das escolas estaduais, que muitas vezes apresenta certa precariedade de recursos, conforme declarado na pesquisa, fato que é percebido pelos docentes como decorrente de vontades externas à instituição, nem sempre por irresponsabilidade da coordenação. A Tabela 1 apresentada anteriormente justifica a situação mostrando que, na maioria das vezes, há um empenho dessas coordenações em ajudar aos professores.

Um fator importante mencionado na pesquisa diz respeito à escassez de recursos financeiros destinados à educação do estado, que se mostra como um empecilho para uma melhor adequação física das escolas.

O quarto questionamento, dirigido aos docentes, refere-se ao tempo disponível para realizar o planejamento de aulas, ou a realização de atividades extracurriculares, levado em consideração o tempo já trabalhado em sala de aula. Para essa questão, conforme Tabela 4, 28\% classificou o tempo como totalmente suficiente, ou seja, não há 
a necessidade de levar trabalho para casa, e é possível elaborar uma boa aula com o tempo disponível.

Tabela 4. O tempo disponível para planejamento e atividades de ensino fora da sala de aula é suficiente em relação a atribuição de aulas?

\begin{tabular}{l|c}
\hline \multicolumn{1}{c|}{ Alternativas } & Porcentagem de respostas \\
\hline Não é suficiente. & $12 \%$ \\
Razoavelmente suficiente. & $60 \%$ \\
Totalmente suficiente. & $28 \%$ \\
\hline
\end{tabular}

Fonte. Elaborado pelos autores, com base nos dados da pesquisa (2019)

Porém $60 \%$ classificou o tempo como razoavelmente suficiente, ou seja, em alguns momentos talvez seja possível elaborar aulas ou participar de atividades extracurriculares, contudo, tal disponibilidade de tempo se faz rotina, o que não é ideal, já que o profissional pode se sentir incapaz de elaborar boas aulas, influenciando diretamente na qualidade do ensino e em sua satisfação. E para $12 \%$ o tempo disponível é totalmente insuficiente, estando então sobrecarregados de tarefas, causando os mesmos efeitos citados acima, e acarretando também ou na ausência de um tempo livre para descanso ou na má elaboração de aulas que prejudicam diretamente o ensino, devido à sobrecarga.

Analisando o quinto questionamento, percebe-se na Tabela 5 que a quantidade de alunos por sala de aula dificulta a realização de aulas dinâmicas, e impossibilita a atenção individualizada, gerando o estresse dos professores, que em muitos momentos precisam se desgastar para chamar atenção de alunos que não estão interessados em conteúdo.

Tabela 5. É possível realizar uma aula produtiva levando em consideração a quantidade de alunos por sala?

\begin{tabular}{lcc}
\hline & Alternativas & Porcentagem de respostas \\
\hline Sim. & & $42 \%$ \\
Não. & $58 \%$ \\
\hline
\end{tabular}

Fonte. Elaborado pelos autores, com base nos dados da pesquisa (2019)

Foram tabulados que 58\% dos professores se encontram do modo descrito acima, ou seja, dar aulas muitas vezes se torna algo extremamente desgastante até mesmo improdutivo. Porém, apesar do percentual negativo ser um dado preocupante, $42 \%$ estão conseguindo ministrar aulas levando em consideração a quantidade de alunos. Neste caso, é importante que as escolas apresentam estruturas capazes de fazer a distribuição correta do número de alunos por sala de aula.

Por meio da Tabela 6, percebe-se que a atuação dos docentes não está restrita somente à área de formação. Apesar de $63 \%$ confirmar a atuação em sua área, $37 \%$ mencionou a atuação em disciplinas de outras áreas, fato indesejado, apesar de serem áreas correlatas, pois é importante que esse percentual seja baixo, tendo em vista que os professores não são capacitados para ministrarem aulas fora de sua área específica de formação. Além de haver prejuízo aos alunos, o próprio professor se sentirá insatisfeito.

Tabela 6. Sua atuação docente está restrita à sua área de formação?

\begin{tabular}{lcc}
\hline & Alternativas & Porcentagem de respostas \\
\hline Sim. & $63 \%$ \\
Não. & $37 \%$ \\
\hline
\end{tabular}

Fonte. Elaborado pelos autores, com base nos dados da pesquisa (2019) 
A sétima pergunta, cujas respostas estão na Tabela 7, refere-se a presença de estímulos para que professores participem de projetos, sendo esses estímulos fundamentais dado que já foi percebido a importância de desafiar trabalhadores e fazer com que saiam um pouco da rotina de realizar o mesmo todos os dias (ANTUNES; PRAUN, 2015).

Tabela 7. Os professores são estimulados a participar de projetos?

\begin{tabular}{lc}
\hline \multicolumn{1}{c}{ Alternativas } & Porcentagem de respostas \\
\hline Não se aplica de nenhum modo. & $0 \%$ \\
Pouco se aplica. & $20 \%$ \\
Aplica-se razoavelmente. & $30 \%$ \\
Aplica-se bastante. & $32 \%$ \\
Aplica-se totalmente. & $18 \%$ \\
\hline
\end{tabular}

Fonte. Elaborado pelos autores, com base nos dados da pesquisa (2019)

Observando os resultados obtidos, $50 \%$ dos docentes considera-se bastante ou totalmente estimulado a participar de projetos, em contrapartida há um grupo de $50 \%$ que está razoavelmente ou pouco estimulado a participar. Mesmo diante da declaração de $50 \%$ dos professores satisfeitos com este quesito não deixa de ser um bom dado para a educação, já que além de benefícios aos professores, também há benefícios à sociedade como um todo, por meio de projetos e pesquisas. Porém, 50\% representa um outro percentual preocupante, uma vez que há interesse de professores realizarem pesquisas, mas não conseguem aproveitar essas oportunidades por falta de motivação por parte da direção das escolas, pelos próprios colegas professores ou até mesmo pelos próprios alunos.

O oitavo questionamento, dirigido aos docentes, relaciona-se com a satisfação de modo geral no ambiente de trabalho, tanto em relações sociais quanto na estrutura física

das instituições. Pela Tabela 8, constata-se que $13 \%$ deste total está totalmente satisfeito com o ambiente de trabalho, 55\%, apresenta-se estar razoavelmente ou bastante satisfeito com o local de sua profissão e $2 \%$ pouco satisfeito. Os resultados apontam uma satisfação positiva, porém, os docentes ainda estão longe de alcançarem um ideal em que seja possível sustentar uma organização de forma positiva com ensino de qualidade, visto que apenas $13 \%$ não possui problemas relacionados à satisfação no ambiente em que trabalha.

Tabela 8. Levando em consideração o seu ambiente de trabalho, envolvendo relações sociais e estrutura física, você está?

\begin{tabular}{l|c}
\hline \multicolumn{1}{c|}{ Alternativas } & Porcentagem de respostas \\
\hline Totalmente insatisfeito. & $0 \%$ \\
Pouco satisfeito. & $2 \%$ \\
Razoavelmente satisfeito. & $40 \%$ \\
Bastante satisfeito. & $45 \%$ \\
Totalmente satisfeito. & $13 \%$ \\
\hline
\end{tabular}

Fonte. Elaborado pelos autores, com base nos dados da pesquisa (2019)

Analisando a parte discursiva da questão aberta do questionário, sete docentes dos 40 participantes da pesquisa deixaram contribuições que julgaram ser necessárias, dentre essas estão a falta de laboratórios e equipamentos para trabalhar as matérias de ciências da natureza, a impossibilidade de realizar práticas mais elaboradas, e também a questão 
da redução orçamentária que impactou o número de contratos, dificultando assim o uso do laboratório de informática pela falta de funcionários.

Outro ponto abordado nas respostas foi a quantidade de alunos por sala de aula, que dificulta o trabalho desses professores. Todos os fatores citados, refletem em índices de insatisfação.

\section{CONSIDERAÇÕES FINAIS}

Com base nos dados apresentados anteriormente, é possível julgar a satisfação como uma das principais vertentes para o bom desenvolvimento organizacional, uma vez que ela é responsável pelas atitudes dos colaboradores no meio de trabalho, as quais impactam diretamente no exercício de sua função, sendo responsáveis pela estabilidade da instituição.

A principal limitação encontrada na realização desta pesquisa consistiu em reunir uma amostra, tendo em vista que muitos dos profissionais questionados alegavam não ter tempo disponível devido ao cotidiano carregado de atividades. No entanto, após explicar a importância do estudo, grande parte se disponibilizou a responder. Diante de tal situação, pode-se perceber que são parcos os esforços destinados às pesquisas acadêmicas dentro do contexto da educação no Município.

Partindo para a ótica da pesquisa aplicada, nota-se, em visão geral, que apesar do equilíbrio dos dados coletados, os resultados apontam uma leve predominância de que os entrevistados estão satisfeitos com a execução de seu trabalho. Mesmo diante de algumas discordâncias, como a falta de infraestrutura ou até o desinteresse por parte dos discentes, é perceptível que os docentes se sentem bem em seu local de trabalho.

Apesar disso, é importante um olhar para os aspectos que precisam ser aprimorados para que o trabalho de docência seja exercido com êxito. A maior aproximação e interação com órgãos governamentais em relação à infraestrutura ou até mesmo na gestão dessas instituições, por meio da mudança do corpo diretor, são medidas que podem levar à renovação no clima organizacional podendo elevar a satisfação dos professores com um sentimento positivo em relação ao trabalho.

Por meio desse estudo, abre-se espaço para comparativos com futuras pesquisas no mesmo campo de análise, podendo os dados serem reutilizados para a criação de índices de satisfação dos docentes, de modo a apontar se o sistema educacional nesse ponto apresentará melhorias ou não. Também, possibilitam-se novos estudos no munícipio, já havendo, dessa forma, dados a respeito das escolas estaduais, que poderão ser comparados com a satisfação de professores de escolas particulares ou da rede federal na cidade. Outro ponto que também se mostra potencial a ser considerado é a comparação das escolas estaduais entre municípios do estado de Mato Grosso, criando-se assim um banco de dados com o intuito de facilitar a identificação e resolução de problemas ao comparar com outras cidades.

O resultado do trabalho foi satisfatório à medida que cumpriu com a proposta, tendo alcançado os objetivos. Oportunizou o entendimento das limitações e desafios enfrentados na função dos docentes da área estudada. Para os autores, ampliou a visão, à medida que aplicou conhecimentos de gestão de recursos humanos no contexto educacional. 


\section{REFERÊNCIAS}

ALVES, M. G.; AZEVEDO, N. R.; GONCALVES, T. N. R.. Satisfação e situação profissional: um estudo com professores nos primeiros anos de carreira. Educação e Pesquisa, São Paulo, v. 40, n. 2, p. 365-382, jun. 2014.

ANTUNES, R.; PRAUN, L.. A sociedade dos adoecimentos no trabalho. Serviço Social \& Sociedade, São Paulo, n. 123, p. 407-427, set. 2015.

BOY; DUARTE. A dimensão coletiva do trabalho docente: uma experiência em duas escolas municipais de Belo Horizonte. Educação em Revista, Belo Horizonte, v.30, n.04, p. 81-104, dez. 2014.

BOGLER, R.; NIR, A. E.. The importance of teachers' perceived organizational support to job satisfaction. Journal Of Educational Administration, [s.1.], v. 50, n. 3, p.287306, mai. 2012.

COUTINHO, M. C.. Participação dos trabalhadores: um estudo sobre as práticas e as representações em uma organização participativa. Psicologia em Estudo, Maringá, v. 7, n. 2, p. 101-109, dez. 2002.

FERREIRA, A. C. M.. Satisfação no Trabalho de Docentes de Uma Instituição Pública de Ensino Superior: Reflexos na Qualidade de Vida. 2011. 126 f. Dissertação (Mestrado) - Curso de Enfermagem, Faculdade de Enfermagem, Universidade Federal de Goiás, Goiânia, 2011.

GARCIA, Á. L.; OLIVEIRA, E. R. A.; BARROS, E.. Qualidade de vida de professores do ensino superior na área da saúde: discurso e prática cotidiana. Cogitare Enfermagem, [s.1.], v. 13, n. 1, p.18-24, 5 ago. 2008.

GIL, A. C. Como elaborar projetos de pesquisa. São Paulo: Atlas, 2007.

HERZBERG, F.. One More Time: How Do You Motivate Employees?. Job Satisfaction - A Reader, [s.1.], p.17-32, 1976. Palgrave Macmillan UK.

KLASSEN, R. M.; USHER, E. L.; BONG, M. Teachers' Collective Efficacy, Job Satisfaction, and Job Stress in Cross-Cultural Context. The Journal Of Experimental Education, [s.1.], v. 78, n. 4, p.464-486, 24 jun. 2010. Informa UK Limited.

LIMA, P. G.; SANTOS, S. M. O coordenador pedagógico na educação básica: desafios e perspectivas. Educere Et Educare: Revista de Educação, Cascavel, v. 2, n. 4, p.77-90, jul. 2007.

MINAYO, M. C. S. (org.). Pesquisa Social. Teoria, método e criatividade. 18 ed. Petrópolis: Vozes, 2001. 
PEREIRA, C.A.A.,ENGELMANN, A. Um estudo da qualidade de vida universitária no trabalho entre docentes da UFRJ. Arquivos brasileiros de psicologia, v. 45, n. 3, p.1248, jul. 1993.

PIZZOLI, L. M. L.. Qualidade de vida no trabalho: um estudo de caso das enfermeiras do Hospital Heliópolis. Ciência \& Saúde Coletiva, Rio de Janeiro, v. 10, n. 4, p. 10551062, dez. 2005.

RAMOS, M. F. H. et al. Satisfação no trabalho docente: Uma análise a partir do modelo social cognitivo de satisfação no trabalho e da eficácia coletiva docente. Estudos de Psicologia, [s.1.], v. 21, n. 2, p.179-191, jun. 2016. GN1 Genesis Network.

REBOLO, F.; BUENO, B. O. O bem-estar docente: limites e possibilidades para a felicidade do professor no trabalho. Acta Scientiarum. Education, [s.1.], v. 36, n. 2, p.427-435, 7 jul. 2014. Universidade Estadual de Maringá.

ROBBINS, S. P.; JUDGE, T. A.; SOBRAL, Filipe. Comportamento Organizacional: teoria e prática no contexto brasileiro. 14. ed. São Paulo: Person Education Brasil, 2010.

SIQUEIRA, M. M. M.. Medidas do comportamento organizacional: ferramentas de diagnóstico e de gestão. Porto Alegre: Artmed, 2008.

SIQUEIRA, M. M. M.; PADOVAM, Valquiria Aparecida Rossi. Bases teóricas de bemestar subjetivo, bem-estar psicológico e bem-estar no trabalho. Psicologia: Teoria e Pesqquisa, Brasília, v. 24, n. 2, p. 201-209, jun. 2008.

SPECTOR, P. E. Psicologia nas organizações. São Paulo: Saraiva, 2003.

ZANELli, J. C.; BORGES-ANDRADE, J. E.; BASTOS, A. V. B. Psicologia, organizações e trabalho no Brasil. Porto Alegre: Artmed, 2004. 